\title{
Sub-lethal toxicity and elimination of the cocaine metabolite, benzoylecgonine: a narrative review
}

\author{
Jiye Wang ${ }^{1 \#}$, Xingyu Deng ${ }^{2,3 \#}$, Yanan $\mathrm{Wu}^{2,3}$, Yuyu Huang ${ }^{4}$, Shurong $\mathrm{Hou}^{2,3}$, Yun Zhang ${ }^{2,3}$, Ting Qiu , \\ Junsen Tong ${ }^{2,3}$, Xiabin Chen ${ }^{2,3}$
}

${ }^{1}$ Key Laboratory of Drug Prevention and Control Technology of Zhejiang Province, Zhejiang Police College, Hangzhou, China; ${ }^{2}$ College of Pharmacy, School of Medicine, Hangzhou Normal University, Hangzhou, China; ${ }^{3}$ Key Laboratory of Elemene Class Anti-Cancer Chinese Medicines; Engineering Laboratory of Development and Application of Traditional Chinese Medicines; Collaborative Innovation Center of Traditional Chinese Medicines of Zhejiang Province, Hangzhou Normal University, Hangzhou, China; ${ }^{4}$ Department of Pharmacy, Affiliated Hospital of Hangzhou Normal University, Hangzhou, China; ${ }^{5}$ Hangzhou Jiubao Biotechnology Co. Ltd., Hangzhou, China

\#These authors contributed equally to this work.

Contributions: (I) Conception and design: X Chen, J Tong; (II) Administrative support: X Chen, J Tong; (III) Provision of study materials or patients: J Wang, X Deng; (IV) Collection and assembly of data: J Wang, X Deng, J Tong; (V) Data analysis and interpretation: J Wang, X Deng, J Tong, Y Wu, Y Huang, S Hou, Y Zhang, T Qiu; (VI) Manuscript writing: All authors; (VII) Final approval of manuscript: All authors.

Correspondence to: Junsen Tong, PhD. College of Pharmacy, School of Medicine, Hangzhou Normal University, Hangzhou 311121, China. Email: junsentong@hznu.edu.cn; Xiabin Chen, PhD. College of Pharmacy, School of Medicine, Hangzhou Normal University, Hangzhou 311121, China. Email: xch226@hznu.edu.cn.

\begin{abstract}
Cocaine abuse is a serious global public health and social problem, and cocaine detoxification remains a challenge. Benzoylecgonine (BE) is the main toxic metabolite after cocaine consumption, with a longer retention time in the body and environment than cocaine itself. According to many studies, the toxicity of BE to humans is as significant as cocaine itself. Moreover, BE is recognized as an addictive drug contaminant in the environment, especially the freshwater system, leading to worries of its ecotoxicity. Extensive studies on the adverse effects of $\mathrm{BE}$ on both humans and ecology have been conducted, showing a marked sub-lethal toxicity of BE to diverse organisms. To eliminate BE in vivo and in vitro, various elimination methods have been developed and their BE removal capacity were evaluated. In this review, we aimed to summarize information in the literature to understand better BE toxicity and elimination that may facilitate the clinical treatment of cocaine abuse. By studying the critical role of BE in cocaine abuse, we propose that the ideal treatment for cocaine abuse should not only detoxify cocaine itself but also remove or degrade BE. Emphasizing the necessity of developing effective BE elimination methods is significant for the development of potential clinical treatments and environmental protections.
\end{abstract}

Keywords: Benzoylecgonine (BE); cocaine abuse; toxicity; ecotoxicity; elimination methods

Submitted Jan 28, 2021. Accepted for publication May 13, 2021.

doi: 10.21037/apm-21-243

View this article at: http://dx.doi.org/10.21037/apm-21-243

\section{Introduction}

Cocaine abuse remains a significant worldwide public health problem with serious socio-economic consequences. According to the latest World Drug Report (1), $0.4 \%$ of the global population aged 15-64 (around 19 million people) reported having used cocaine in 2018. In addition to its intense excitatory effect on the nervous system, cocaine has non-negligible adverse effects on the cardiovascular, gastrointestinal, respiratory, musculoskeletal and renal systems (2,3). After consumption, approximately $40 \%$ of cocaine is rapidly biotransformed into inactive metabolite ecgonine methyl ester (EME) by plasma enzyme butyrylcholinesterase (BChE) and liver enzyme 


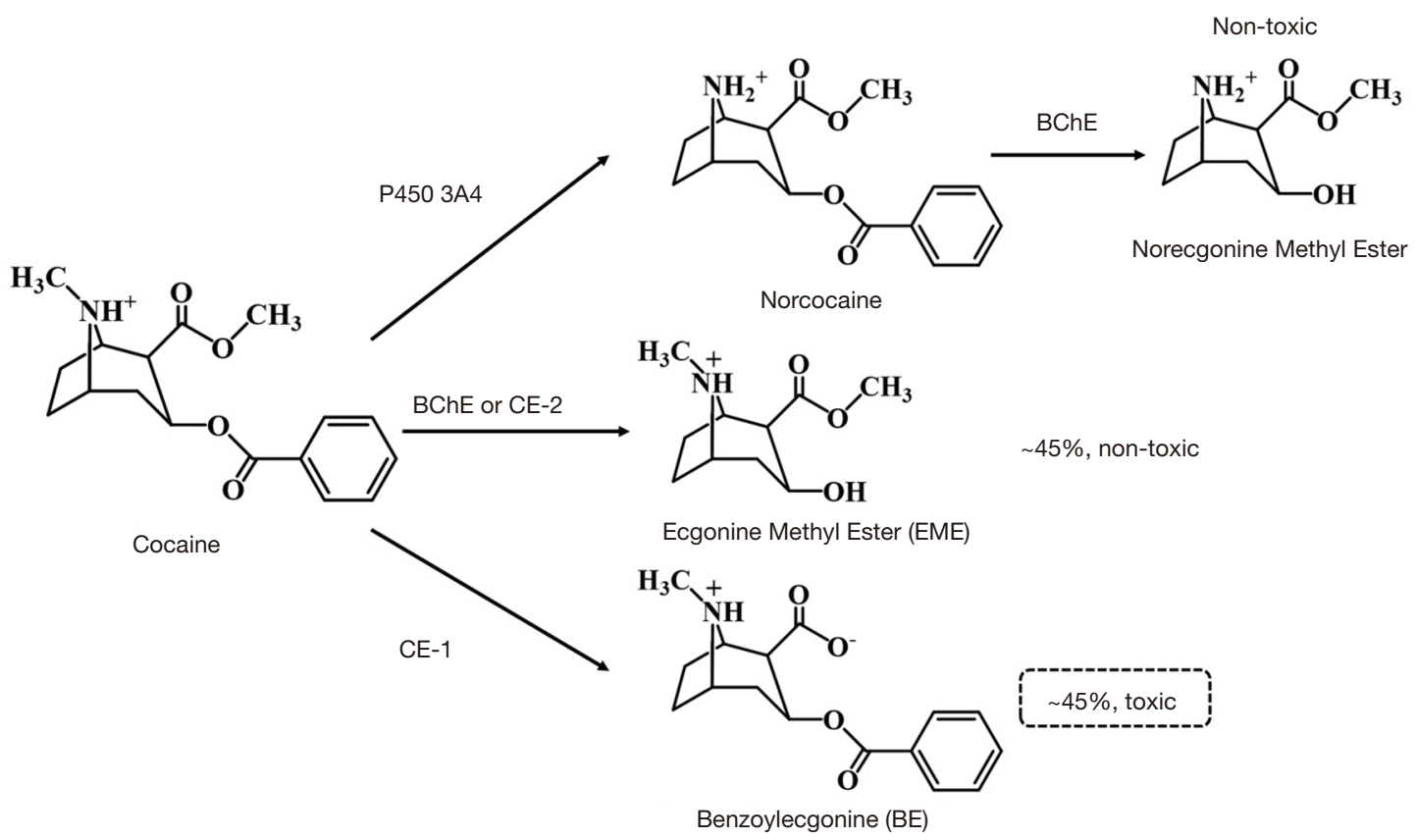

Figure 1 Benzoylecgonine is the main toxic metabolite of cocaine. Approximately $45 \%$ of cocaine is hydrolyzed to benzoylecgonine (BE) by carboxyesterase-1 (CE-1) in liver; $40 \%$ of cocaine is biotransformed to inactive metabolite ecgonine methyl ester (EME) by plasma enzyme butyrylcholinesterase (BChE) and liver enzyme carboxyesterase-2 (CE-2).

carboxyesterase-2 (CE-2), while $45 \%$ of cocaine is hydrolyzed to a toxic metabolite benzoylecgonine (BE) by carboxyesterase-1 (CE-1) in the liver (Figure 1) (4).

$\mathrm{BE}$ is an active metabolite with sub-lethal toxicities on multiple targets. A previous in vivo study showed that $\mathrm{BE}$ is a stronger vasoconstrictor than cocaine itself (5), hence the cerebral arteries are more sensitive (6). According to another study, the incidence of seizure is highly related to the presence of $\mathrm{BE}(7)$. Also, the latest research has found that even low concentrations of BE can significantly change the expression levels of proteins related to calcium homeostasis and oxidative emergency (8). These studies pointed out that $\mathrm{BE}$ has remarkable sub-lethal toxic effects in vivo.

Moreover, BE can remain in the body for a considerably longer period compared to the parent drug and can be detected in urine up to 4 days after last cocaine use. For this reason, $\mathrm{BE}$ is commonly used as a marker to screen individuals for a history of cocaine consumption or estimate the scale of the cocaine market (9). BE is poisonous and exhibits durable influences, which means that the removal or degradation of it into biologically inactive molecules is critical for cocaine detoxification.
$\mathrm{BE}$ is often excreted from the urine as one of the major substance forms of cocaine, and the environment is the ultimate destination. Unlike cocaine, $\mathrm{BE}$ is an amphoteric ion which is extremely stable in the human body and the natural environment (10). Consequently, the expelled $\mathrm{BE}$ is often detected in urban water systems in western and central European cities (1). Based on a wastewater analysis provided by Sewage Analysis CORe group Europe (SCORE), BE was found in the wastewater in 136 cities (150 sites) in Europe. In 2019, the amounts of population-normalized mass loads identified reached $225 \mathrm{mg}$ /day per 1,000 inhabitants (1). According to more accurate reports, BE concentrations in the inlets and outlets of wastewater treatment plants (WWTPs) reached 7,500 and 3,425 ng/L, respectively $(10,11)$. BE then enters the receiving water bodies including surface water, ground water and even drinking water sources, as proven by several monitoring studies. Even if $\mathrm{BE}$ concentration in the natural environment is low (for instance, $316 \mathrm{ng} / \mathrm{L}$ in one study) (10), the potential adverse effects on non-target organisms cannot be ignored. A mixture of illicit drugs containing $300 \mathrm{ng} / \mathrm{L} \mathrm{BE}$ could alter the oxidative status of the zebra mussels, causing genetic damage and oxidative stress $(12,13)$. A more recent study 
on Mediterranean mussels found that $500 \mathrm{ng} / \mathrm{L}$ cocaine and $20 \mathrm{ng} / \mathrm{L}$ BE induced an oxidative stress situation both independently and in the mixture (14). The eco-toxicity of $\mathrm{BE}$ on diverse model aquatic species was evaluated at concentrations similar to those detected in surface waters (13,15-17). Increased evidence has confirmed that BE exhibits significant toxic effects on aquatic animals and plants. More importantly, it is reasonable to speculate that sustaining BE exposure in the environment could influence animals, plants, crops in the food chain and ultimately influence humans.

Given the sub-lethal toxic effects of $\mathrm{BE}$ on humans and the environment, there is a pressing need to identify efficient methods to either adsorb or degrade it in situ. Techniques such as active sludge reactors, reactive barrier, Fenton reaction, hydrogen peroxide $\left(\mathrm{H}_{2} \mathrm{O}_{2}\right)$ treatment, ozone oxidation, and enzymatic degradation have been developed to transform BE into non-toxic products $(18,19)$. Multiple technologies are usually incorporated to increase the removal efficiency against illicit drugs and their metabolites during water treatment (19). In recent years, enzymatic degradation is a useful strategy for BE detoxification both in vivo and in vitro (18). The effective enzymes against $\mathrm{BE}$ are suitably used in environmental protection by developing transgenic plants. BE elimination for humans and the environment has hopefully attracted attention and become a key aspect in cocaine abuse treatment.

The purpose of this study was to review the current literature concerning the toxicity of cocaine's principle metabolite, BE, as well as its elimination methods both inside and outside the body. This study aimed to describe possible solutions to prevent further toxic effects of $\mathrm{BE}$ during cocaine detoxification treatment. The discovery and development of highly effective methods for cocaine detoxification treatment are critical.

We present the following article in accordance with the Narrative Review reporting checklist (available at http:// dx.doi.org/10.21037/apm-21-243).

\section{Methods}

The current review was carried out by an inclusive search in PubMed, using any combination of the following search terms: "benzoylecgonine", "cocaine abuse" and "toxicity". The search was not limited to either Englishlanguage articles or publication date. Ninety-two articles were found and evaluated for inclusion independently by both authors and journals. Seventy-seven articles with strong relationships were selected for detailed evaluation. We did not assess the quality of the included studies. After the search, we constructed a list depending on the areas presented in the included studies. The first authors conducted an initial screening of the included studies by reading the titles and abstracts and decided whether they were relevant for our purposes. The entire team then carried out a second screening of the full-texts. Ultimately, detailed information was selected and presented here.

\section{Toxicity of BE}

\section{Toxicity of BE in humans}

Cocaine toxicity has been studied extensively, as has been shown in previous reviews (3), yet BE toxicity has been less explored. However, according to limited toxicology studies, $\mathrm{BE}$ exhibits different mechanisms of adverse effects on the cardiovascular system, nervous system and infants (Figure 2). Importantly, BE seems more toxic to certain organs such as cerebral arteries and infants. Moreover, chronic cocaine toxicity might be due to the presence of its toxic metabolite $\mathrm{BE}$. Thus, it is necessary to re-estimate the toxic effects of $\mathrm{BE}$ in vivo.

\section{Vasoconstriction}

Clinically, cocaine is a vasoconstrictor. However, it has been reported that $\mathrm{BE}$ has more vasoconstriction effects compared to the parent drug and other drugs such as norcocaine and norepinephrine (5). BE has been shown to cause a significant decrease in the arterial diameter of isolated cerebral arteries of cats and fetal sheep $(6,20,21)$. Cerebral artery segments are more sensitive to $\mathrm{BE}$ than cocaine and other cocaine metabolites (6). A previous in vitro study has demonstrated that $\mathrm{BE}$ cause a $30.1 \% \pm 4.96 \%$ decrease in arterial diameter of at a concentration of $10^{-5} \mathrm{M}(20)$.

Furthermore, a study has suggested that the constricting effect of $\mathrm{BE}$ is mediated via $\alpha 1$-adrenergic receptor stimulation (6), which is identical to the mechanism of cocaine-induced vasoconstriction. However, another study pointed out cocaine and $\mathrm{BE}$ exert vasoconstrictor effects through different mechanisms. This study reported that cocaine primarily activates adrenergic nerves and receptors, coupled with intracellular $\mathrm{Ca}^{2+}$ store activation, whereas $\mathrm{BE}$ seems to cause an influx of extracellular $\mathrm{Ca}^{2+}$ to increase the intracellular $\mathrm{Ca}^{2+}$ level (21). Cocaine was also reported to cause vasoconstriction by stimulating the sympathetic 


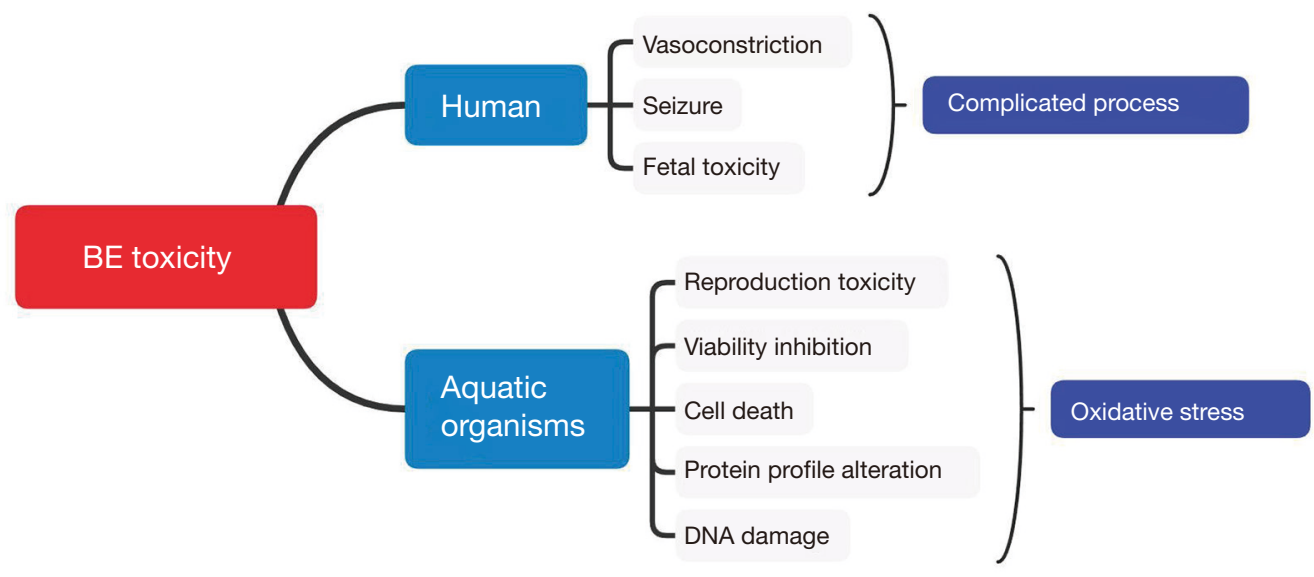

Figure 2 Sublethal toxicity of BE to human and aquatic organisms. BE shows strong vasoconstriction effect in body, induces seizures and fetal toxicity in mechanisms that are different to cocaine. BE also has significant adverse effects on aquatic animals and plants, such reproduction toxicity, viability inhibition, cell death effect via inducing oxidation stress.

nervous system, followed by decreasing the reuptake of neurotransmitters including dopamine, epinephrine and norepinephrine (22). BE induced vasoconstriction is mediated by several complicated mechanisms that require further investigation. Furthermore, BE-induced vasoconstriction may be involved in other sub-lethal toxicities such as neurotoxicity and cardiovascular disease.

\section{Chronic neurotoxicity}

Cocaine-induced seizures commonly occur after cocaine consumption and are characterized by intense brain activity and repeated or rhythmic jerking muscle movements. Seizures have always been considered one of the serious effects of cocaine poisoning, in addition to psychosis and cardiovascular effects (2,23-27). Cocaine is a psychostimulant and psychotomimetic compound (28) that may induce acute and chronic psychiatric and neurological effects, including psychosis, agitation and seizures (29). The mechanisms underlying the neurotoxicity of cocaine are not fully understood since several intracellular biochemical processes appear to be involved (30-32). However, BE is assumed to be responsible for seizures, as cocaine only has a 6 hours half-life in the body, whereas seizure usually occurs later after cocaine intake $(7,33)$. Scientists assume that BE-induced seizures occur via different mechanisms (26). Compared to equimolar amounts of cocaine, BE-induced seizures occur more frequently and have a significantly longer latency (7). In behavioral studies of rats, the frequency of seizures and the length of latency were directly related to the dose of $\mathrm{BE}$, with the frequency of seizures increasing from $33 \%$ to $86 \%$, as well as a significantly decreased latency when the dose of $\mathrm{BE}$ was increased from 45 to $180 \mu \mathrm{g}(33)$.

\section{Fetal toxicity}

$\mathrm{BE}$ could also inhibit embryos from developing into blastocysts at one or two cellular stages (34). Also, BE causes maternal and fetal hypertension (35). This phenomenon may be correlated to the afore mentioned vasoconstrictive effect of $\mathrm{BE}$, and in the infant's brain, it could also lead to ischemic events or strokes, resulting in permanent neurological damage (33). A previous study has shown that infants and neonates exhibit signs of "neuroexcitation" following exposure to cocaine. However, BE was found in the urine and not cocaine. Cocaine was only detected in the urine of lethargic newborns (36). Therefore, some studies hypothesized that $\mathrm{BE}$ might cause behavioral changes in newborns and their hypotheses had been confirmed (37). Due to the incomplete development of the blood-brain barrier, the effect of $\mathrm{BE}$ on the fetal brain may be greater than the maternal effects. In pharmacokinetic studies, the concentration of $\mathrm{BE}$ in the fetal brain was higher than in the maternal brain (38-40), which is consistent with the differences in fetal and maternal bodies (41). A clinical study demonstrated that BE could persist in the urine of neonates for up to 48-120 hours after exposure but only persists for 27 hours in the urine of adults (41). The placenta may cause this phenomenon since $\mathrm{BE}$ is retained by the placenta and then subsequently leaches 
into the fetal and maternal circulation (42).

\section{Ecotoxicity of BE}

\section{Toxicity to freshwater animals}

Parolini et al. assessed the consequences of $\mathrm{BE}$ exposure on Daphnia magna, a toxicological test species for water systems. The swimming activity of individuals and the reproduction of the population were investigated at two concentrations of BE $(0.5$ and $1.0 \mu \mathrm{g} / \mathrm{L})$, which are similar to the levels previously detected in aquatic ecosystems (10). At high BE concentrations, the activity of D. magna showed a $5 \%$ reduction; however, the swimming velocity increased marginally (15). The chronic toxicity test showed that the total number of offspring ( $43 \%$ and $39 \%$ lower) and parthenogenetic cycles ( $45 \%$ and $21 \%$ lower) were significantly decreased at both concentrations of $\mathrm{BE}$, respectively, indicating the strong reproductive toxicity of BE on D. magna (15). BE exposure also induced a marked increase in apoptotic or necrotic cell frequency at a concentration of $1.0 \mu \mathrm{g} / \mathrm{L}$, showing values of up to 2.5 - and 3 -fold higher than the control $(17,43)$.

$\mathrm{BE}$ exposure also induced a notable increase in cell mortality. In zebrafish embryo cells, cell mortality was significantly increased at $\mathrm{BE}$ concentration of above $0.4 \mathrm{nM}$ (43). In C. elegans cells, according to the cell mortality results at different $\mathrm{BE}$ concentrations, the $\mathrm{EC}_{50}$ of $\mathrm{BE}$ was estimated as $0.6 \pm 0.1 \mathrm{ppm}$ (44). A notable increase in the size of lipid droplets of $D$. magna at their juvenile stage was observed after BE exposure at concentration of $3.5 \times 10^{-3}$ M. The accumulated lipid droplets indicated abnormal lipid synthesis or metabolism (44).

Furthermore, a proteomics study showed that exposure to $\mathrm{BE}$ for 14 days changed the protein profile of the gills of $D$. polymorpha (8). Diverse proteins involved in different systems had also shown alteration. Two actin isoforms and another protein, moesin, which is related to cytoskeleton structure, were also over-expressed at a BE concentration of $1 \mu \mathrm{g} / \mathrm{L}$ (8). The normally low-expressed actin isoforms take part in multiple important cell survival processes, such as structure conservation, motility, cellular organization and intracellular transport (45). Moesin is an integrin that plays biological roles in regulating basic cellular functions, including motility, adhesion, cellular signaling and cellular morphology (46). Exposure to BE also affected calcium homeostasis. The precursor of calreticulin was found to be over-expressed at the tested BE concentrations.
Calreticulin forms calnexin/calreticulin complexes and promotes proper folding, assembling and maturation of proteins (8). Proteins affecting apoptosis, like Galectin 7, were over-expressed at even lower concentrations of $\mathrm{BE}$ $(8,47)$. Adenosyl-homocysteinase was over-expressed at two BE concentrations, affecting amino acid metabolism $(8,48)$. The expression of two enzymes involved in glycolysis, namely enolase and GAPDH, were down-regulated after $\mathrm{BE}$ exposure, suggesting that $\mathrm{BE}$ may reduce the tolerance of zebra mussels to environmental stresses by decreasing energy metabolism $(8,49)$. Low expression of EF-2, a protein involved in protein biosynthesis, was speculated to disrupt the metabolic pathways of zebra mussels and subsequently reduce the resistance to environmental changes $(8,49)$.

Regarding another aquatic species, Parolini et al. found that exposure to a low concentration of BE $(0.3 \mu \mathrm{g} / \mathrm{L}$, respectively) would significantly alter the protein profile of zebrafish embryos during the early developmental period (96 hours after fertilization). Proteins belong to eye lens constituents, lipid transport and energy metabolism were also significantly altered in the $\mathrm{BE}$ group and the cocaine and EME groups (16). Also, exposure to high BE concentration $(1 \mu \mathrm{g} / \mathrm{L}$, respectively) had additional effects on proteins involved in lipid metabolism and oxidative stress response (16). This alteration was only observed for BE and EME, not cocaine (16).

Not only proteins but DNA was also be damaged due to $\mathrm{BE}$ exposure. A significant increase of DNA fragmentation in cells from $D$. polymorpha was observed by measuring the value of ligase detection reaction at $\mathrm{BE}$ concentrations of 0.5 and $1.0 \mu \mathrm{g} / \mathrm{L}$, showing values $52 \%$ and $60 \%$ higher than the control, respectively (17). Significant DNA strand break was also observed in embryo cells at tested concentrations from 0.04 to $40 \mathrm{nM}$ (43). Regarding fixed DNA damage, apoptotic, necrotic and micronuclei frequency increased, which followed both time and concentration dependencies $(17,43)$.

Solid evidence has suggested that the adverse effects to macromolecules are mainly caused by BE-induced oxidative stress. In 2013, Parolini et al. investigated BE-induced oxidation on the freshwater mussel, D. polymorpha. In their study, the neutral red retention assay showed a significantly decreased trend of lysosomal membrane stability at both tested concentrations $(0.5$ and $1.0 \mu \mathrm{g} / \mathrm{L}$, respectively) in a time and dose-dependent manner (17), suggesting a situation of general cellular stress likely linked to the induction of oxidative stress (50). For detailed biomarkers, the activities of three antioxidant phase I enzymes, namely 
catalase (CAT), superoxide dismutase (SOD) and glutathione peroxidase (GPx), as well as the phase II detoxifying enzyme glutathione S-transferase (GST), were altered imbalanced depending on the dose (17). The activities of these defense enzymes were also imbalanced in zebrafish embryo cells after $\mathrm{BE}$ exposure in a concentration range of 0.04 to $40 \mathrm{nM}$ (43). Significant increases of SOD and GPx were recorded at $4 \mathrm{nM}$ $(\sim 1.16 \mu \mathrm{g} / \mathrm{L})(43)$. Clearer patterns of these oxidative status biomarkers were observed on D. magna at consistent $\mathrm{BE}$ concentrations. The reactive oxygen species (ROS) increased $13 \%$ while antioxidant GPx increased $68 \%(15)$. The detoxifying enzyme GST activity increased $80 \%$ and $46 \%$ at 0.5 and $1.0 \mu \mathrm{g} / \mathrm{L}$ of BE, respectively (15). The indirect evidence, obtained by measuring the lipid peroxidation (LPO) and protein carbonyl content (PCC), also indicated that substantial oxidative damages were caused after BE exposure $(15,17,49,51,52)$. Taken together, $\mathrm{BE}$ has been shown to exhibit toxic effects on freshwater animals by elevating ROS levels and interrupting the balance of the antioxidant system. These results suggest that BE-induced oxidative stress may be the major reason for the toxicity of aquatic organisms.

\section{Toxicity to freshwater plants}

The toxicity of BE to freshwater plants has been less studied. However, based on a few studies, BE exposure caused developmental inhibition for certain plants. It was found that $\mathrm{BE}$ exposure caused a decrease in the viability of fern cells. After 48 hours of BE exposure (in a concentration range of 0.001 to $0.01 \mu \mathrm{g} / \mathrm{L}$ ), the mitochondrial activity of P. setiferum fern spores were significantly reduced; however, when the $\mathrm{BE}$ concentration increased to a range of 0.1 to $10 \mu \mathrm{g} / \mathrm{L}$, the mitochondrial activity gradually restored to a normal level. In contrast to the ambiguous result of mitochondrial activity, an approximately $20 \%$ reduction of DNA amount was observed at all test concentrations (53).

Furthermore, BE exposure had a $10 \%$ growth-inhibiting effect on algae $R$. subcapitata at concentrations of $3.5 \times 10^{-3}$ $M$ (44). A previous study had shown that at concentrations of $0.1 \mathrm{M}$ or $3.29 \%$, BE completely inhibited Lupinus albus growth (54). Exposure to BE also induced a high percentage of micronucleated cells in $V$. faba root tips (44).

\section{Elimination of BE}

\section{Biodegradation via activated sludge reactor and reactive barrier}

Conventional activated sludge (CAS) reactors have been widely used in WWTPs for decades $(19,55)$. A laboratory study has demonstrated that $\mathrm{BE}$ (in the range of $500-4,000 \mathrm{ng} / \mathrm{L}$ ) can be efficiently removed in 24 hours using the biological reactor (55). Biodegradation by heterotrophic bacteria contributed $91-95 \%$ of BE removal efficiency since the adsorption, and other abiotic processes were always low (55). Therefore, the activated sludge reactor is commonly used to eliminate $\mathrm{BE}$ and other illicit drugs or their metabolites in the water treatment process, combined with pre-treatment and other methods.

The reactive barrier is another low-cost $\mathrm{BE}$ clearance method. The reactive barrier is set at the bottom of an infiltration basin to promote the adsorption of $\mathrm{BE}$, and consists of aquifer sand, vegetable compost, clay and iron oxide dust (56), and exhibits notable BE removal efficiency. However, the disadvantage of this method is that it takes a long time to completely remove $\mathrm{BE}$, taking about $48 \mathrm{~h}$ in the test (56).

\section{Chemical radical reaction}

Adding $\mathrm{H}_{2} \mathrm{O}_{2}$ to the wastewater to generate $\bullet \mathrm{OH}$ radical could also effectively remove BE (57-60). The formation of $\bullet \mathrm{OH}$ by either continuous exposure to a $\mathrm{UV}_{254}$ lamp or a Fenton reaction is commonly used, with the $\bullet \mathrm{OH}$ radical freely attacking the dissolved organic matter (Figure 3) (57). A study has reported that using the $\mathrm{UV}_{254} / \mathrm{H}_{2} \mathrm{O}_{2}$ process, and staying in the microcapillary film array photoreactor for a few seconds or minutes could effectively remove BE. The Fenton reaction is one of the advanced oxidation processes, which can be used for pretreatment before biological level treatment and can also be used as a tertiary treatment process (58). Chemical reactions that occur in the Fenton reaction or improved Fenton reaction generate the - OH radical, effectively removing BE with an efficiency of approximately $90 \%$ (59). Another study explored the PhotoFenton reaction by using $\mathrm{Fe}_{2} \mathrm{O}_{3}$ /SBA-15 as a heterogeneous catalyst, and the removal efficiency of BE reached $92 \%$ (58). However, the researchers found that the products (peroxides, oxidant by-products) polluted with river water may cause greater toxicity $(44,58,60)$. Therefore, BE by-products produced by peroxide may still exhibit potential toxicity, and this treatment process requires further treatment before discharge.

\section{Oxidation by ozone disinfection}

Ozone oxidation has been mostly applied in drinking 


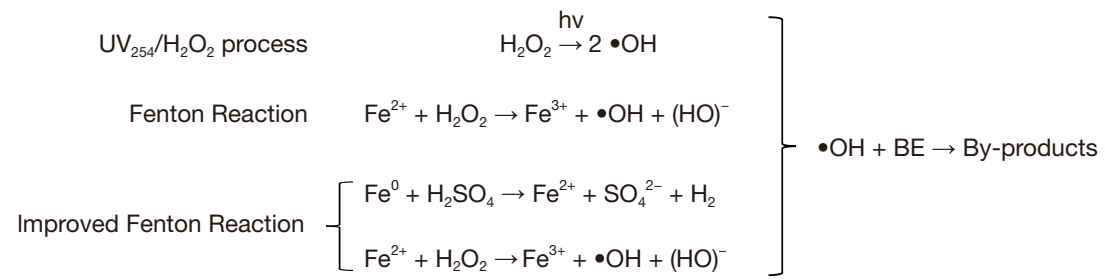

Figure 3 Process/reaction generate $\bullet \mathrm{OH}$ radical effectively remove BE, but produce by-products which may cause more toxicity.

Table 1 Comparison of BE removal efficiency in four WWTPs with different processes

\begin{tabular}{lcccc}
\hline WWTP & Primary & Secondary & Tertiary & Removal efficiency \\
\hline 1 & Sedimentation & CAS with step feed process & No & $95 \% \pm 4 \%$ \\
& & & DAFF $+\mathrm{Cl}_{2}$ & $99 \% \pm 0.2 \%$ \\
2 & No primary sedimentation & SBR & UV & $42 \% \pm 20 \%$ \\
$3 a$ & Sedimentation & CAS with MLE & $\mathrm{Cl}_{2}$ & $82 \% \pm 11 \%$ \\
$3 \mathrm{~b}$ & Sedimentation & 4-stage Bardenpho $+\mathrm{MBR}$ & $\mathrm{UV}$ & $87 \% \pm 9 \%$ \\
4 & Sedimentation & IFAS with MLE & $\mathrm{Cl}_{2}$ & $87 \% \pm 7 \%$ \\
\hline
\end{tabular}

WWTP, wastewater treatment plant; CAS, conventional activated sludge; DAFF, dissolved air flotation-filtration; SBR, sequencing batch reactor; UV, ultra violet; MLE, modified Ludzack-Ettinger; MBR, membrane bioreactors.

water treatment plants (DWTPs), and the efficiency of BE removal has been reported. The first stage of treatment includes chlorination, coagulation/flocculation, and sand filtration provides $9 \% \mathrm{BE}$ removal efficiency. The second stage uses ozone disinfection and oxidation increases efficiency to $43 \%$. The third stage use granulated activated carbon filters and the removal efficiency reached $72 \%$ (61). The overall BE removal efficiency using this three-step clearance was $89 \%$. Researcher believes that the low removal efficiency might be due to the absence of ozonereactive sites and electron-absorbing groups in ozone (61), and similar results were obtained in a study later conducted by another group (62). However, in this study, BE could still be detected in the treated drinking water with an average concentration of $45 \mathrm{ng} / \mathrm{L}$ (the maximum concentration was $130 \mathrm{ng} / \mathrm{L})$. The study continued to carry out toxicological experiments to prove that it was not toxic to humans at this concentration (61). However, according to recent investigations, $\mathrm{BE}$ was still not removed effectively in the DWTPs (63).

\section{Integrated process}

Most WWTPs will combine multiple technologies to remove drugs. Recently, a long-term monitoring program was undertaken in Australia to characterize the fate of emerging drugs of addiction including BE, the major metabolite of cocaine. Different secondary and tertiary treatment technologies were investigated to remove of $\mathrm{BE}$ in sewage (19). WWTP1 comprises a CAS step feed process consisting of anoxic and aerobic zones, which is then subjected to secondary sedimentation/clarification, with a BE removal efficiency of $95 \% \pm 4 \%$. Subsequent three-stage treatment of dissolved air flotation-filtration $(\mathrm{DAFF})$ and chlorination increased the removal efficiency to $99 \% \pm 0.2 \%$, respectively. The treated water could be directly used for horticulture, public place irrigation, and non-potable water purposes (19). The remaining WWTPs adopted a sequencing batch reactor (SBR)/Modified Ludzack-Ettinger (MLE)/4-stage Bardenpho with membrane bioreactors (MBR), or integrated fixed-film activated sludge (IFAS) process followed by UV disinfection or chlorination treatment, which exhibited insufficient BE removal efficiency (19). As shown in Table 1, this work enables a performance comparison between multiple combined wastewater treatment processes.

\section{Enzymatic degradation}

In previous studies, a few efficient and stable cocaine- 
metabolizing enzymes were designed and developed based on human BChE or bacterial cocaine esterase (CocE), which showed rapid detoxification efficiency against cocaine (64-70). For the clinical treatment of cocaine overdose and addiction, using an efficient metabolic enzyme is considered a promising strategy (71-74). However, CocE and its mutants showed no activity against the toxic metabolite $\mathrm{BE}$ while only human $\mathrm{BChE}$ showed activity. Chen et al. demonstrated for the first time that $\mathrm{BChE}$ could hydrolyze $\mathrm{BE}$ into the non-toxic biological metabolites, ecgonine and benzoic acid. To improve the efficiency of BChE, their study constructed mutants to increase the efficiency of hydrolyzing cocaine, and at the same time, increase the degree and rate of $\mathrm{BE}$ degradation in vitro and in vivo (18). In the study, two mutants [A199S/S287G/A328W/Y332G mutant (named E14-3) and A199S/F227A/S287G/A328W/ Y332G mutant (named E12-7)] were shown to have significant increases compared with wild-type BChE (18). Furthermore, in vivo experiments verified that E12-7 accelerated $\mathrm{BE}$ hydrolysis to ecgonine in a dose-dependent manner (18). The BChE-FC fusion or catalytic antibody analogs fusion proteins were further constructed to extend the time of action in the organism. Researchers believe that other mutants with better catalytic activity would be constructed through continuous research (18). The enzymatic degradation of $\mathrm{BE}$ seems to be an effective and eco-friendly elimination method that offers potential in the clinical treatment of cocaine overdose and environmental governance.

\section{Discussion}

$\mathrm{BE}$ is the main toxic metabolite of cocaine after a dose consumption. It has a similar molecular structure to cocaine, which is the major reason for long-term toxicities on the cardiovascular system, central nervous system, fetus, etc. In fact, BE causes more notable decreases in arterial diameter, suggesting it is a more potent vasoconstrictor than cocaine and other drugs, and as a result, cerebral artery segments showed higher sensitivity to BE than cocaine itself. Also, BE-induced seizure has a longer latency and frequency, and thus, seizure incidence after cocaine consumption is supposed to be primarily caused by BE. BE has a strong inhibitory effect on embryos in the early stages of development. Also, BE causes hypertension for both the mother and fetus, which may be correlated with the strong vasoconstrictive effect. In some studies, $\mathrm{BE}$ appears to pass the blood-brain barrier of the newborn more easily, which causes more fetal toxicity.

Moreover, in vitro experiments showed that exposure to $\mathrm{BE}$ decreases cell viability and increases cell mortality, and $20 \mu \mathrm{M}$ of BE exposure results in cell death. At the same time, BE can exist in the body for a relatively long time and is used as an indicator of cocaine consumption. Thus, the toxicity effects of long-term BE exposure in the body should be investigated more extensively.

$\mathrm{BE}$ is one of the major illicit drug metabolites found in the environment, primarily the aquatic system. Considering the increased use of cocaine worldwide and an incessant BE input in freshwater, a consequent increase in concentration is expected. Exposure of BE seems a sort of pseudopersistence to aquatic organisms. Numerous studies have been carried out to evaluated the critical aspect of the environmental risk of BE. Notable adverse effects, such as abnormal synthesis or metabolism of lipids, genetic damage and protein expression alteration, are related to oxidative stress after BE exposure. Importantly, in vivo studies toward aquatic model species, the zebrafish embryos, showed that $\mathrm{BE}$ is more toxic than cocaine. These studies highlighted the relationships between biochemical, behavioral, and reproductive endpoints. In contrast, the studies concerning BE toxicity on plants are few, with growth inhibition being the major adverse effect. The use of BE-polluted surface waters as irrigation and drinking water sources should cause considerable anxiety of persistent exposure of $\mathrm{BE}$ to humans.

Fortunately, numerous methods of BE elimination have been developed and applied in different processes, including wastewater, drinking water, and clinical emergency treatment. WWTPs play a critical role in the removal of $\mathrm{BE}$ to minimize discharge into the receiving environment. Currently, the methods currently used in water treatment processes are activated sludge reactors, photochemical methods, reaction barriers, etc. The removal mechanisms involved are biodegradation, adsorption, photochemistry decomposition, Fenton reaction, etc. Several studies have shown that activated sludge processes with effluent disinfection, such as IFAS with chlorination and MBR with $\mathrm{UV}$, were the most efficient in eliminating the targeted compounds than other more conventional secondary treatment processes. Additional tertiary treatments appear to be effectively achieve near-complete removal of $\mathrm{BE}$ and other drugs in recycled waters destined for agricultural irrigation and other regulated municipal uses. According to the extensive studies, it is highly recommended to apply a CAS step feed process consisting of anoxic and 
aerobic zones, which is critical to reach an acceptable $\mathrm{BE}$ removal efficiency $(>90 \%$, respectively). Additional tertiary stage using dissolved air flotation-filtration (DAFF) and chlorination would increase the removal efficiency to nearly complete in WWTPs. However, DWTPs appear to be not entirely effective in eliminating $\mathrm{BE}$, resulting in human intake. Current technologies in each step have limitations, and a fourth step with advanced technology should be applied for better clearance. Removal methods still require further improvement, and advanced technologies should be expanded globally. For clinical treatment of cocaine overdose, accelerating BE metabolism seems a promising therapy method. A recent study focusing on identifying and engineering the natural enzyme with inherent $\mathrm{BE}$ metabolism activity showed the prospective potential of enzymatic metabolism (18). Human BChE with inherent $\mathrm{BE}$ metabolism activity was redesigned to improve both activity and duration in vivo, the data showed a promising starting point of effective BE metabolism. Emphasizing that $\mathrm{BE}$ is a long-lasting toxic metabolite in vivo, ideal enzyme therapy for cocaine overdose should not only hydrolyze cocaine itself in a short period, but also can degrade BE into non-toxic molecules to prevent persistent toxicity. However, it is still extremely challenging to efficiently treat cocaine overdose using current enzyme products due to the enzyme activity and stability. We expect that new enzymes with higher BE removal efficiency in vivo could be developed for clinical use and environmental governance.

\section{Conclusions}

Findings from the present review showed that $\mathrm{BE}$ is a significant toxic metabolite to humans and the environment. To obtain a better understanding of the adverse effects of $\mathrm{BE}$, more extensive studies focusing on the mechanisms of $\mathrm{BE}$ toxicity are needed in the future. However, according to current research, few studies investigated the potential effects of $\mathrm{BE}$ exposure on humans from the environment. Finally, the BE elimination methods with high removal efficiency are not well-established during water treatment, which may cause subsequent ecotoxicity. More importantly, the clinical treatment of cocaine overdose requires detoxification of cocaine and simultaneous degradation of BE.

\section{Acknowledgments}

Funding: This work was financial supported by the National Science Foundation of China (Grant No. 81803417 and
No. 82073749), National Key Research and Development Program of China (Grant No. 2018YFC0807404 and No. 2016YFC0800906), Open Project Program of Key Laboratory of Drug Prevention and Control Technology of Zhejiang Province (No. 2020011), and the Technology Research Program of the Ministry of Public Security (Grant No. 2016JSYJA32).

\section{Footnote}

Reporting Checklist: The authors have completed the Narrative Review reporting checklist. Available at http:// dx.doi.org/10.21037/apm-21-243

Conflicts of Interest: All authors have completed the ICMJE uniform disclosure form (available at http://dx.doi. org/10.21037/apm-21-243). The authors have no conflicts of interest to declare.

Ethical Statement: The authors are accountable for all aspects of the work in ensuring that questions related to the accuracy or integrity of any part of the work are appropriately investigated and resolved.

Open Access Statement: This is an Open Access article distributed in accordance with the Creative Commons Attribution-NonCommercial-NoDerivs 4.0 International License (CC BY-NC-ND 4.0), which permits the noncommercial replication and distribution of the article with the strict proviso that no changes or edits are made and the original work is properly cited (including links to both the formal publication through the relevant DOI and the license). See: https://creativecommons.org/licenses/by-nc-nd/4.0/.

\section{References}

1. Nations U. World Drug Report 2020 United Nations publication 2020; Sales No. E.20.XI.6. Available online: https://wdr.unodc.org/wdr2020/index.html

2. Heard K, Palmer R, Zahniser NR. Mechanisms of acute cocaine toxicity. Open Pharmacol J 2008;2:70-8.

3. Zimmerman JL. Cocaine intoxication. Crit Care Clin 2012;28:517-26.

4. Beike J. Disposition of toxic drugs and chemicals in man, 7th edn. Int J Legal Med 2005;119:116.

5. Connors NJ, Hoffman RS. Experimental treatments for cocaine toxicity: a difficult transition to the bedside. J Pharmacol Exp Ther 2013;347:251-7. 
6. Schreiber MD, Madden JA, Covert RF, et al. Effects of cocaine, benzoylecgonine, and cocaine metabolites in cannulated pressurized fetal sheep cerebral arteries. J Appl Physiol (1985) 1994;77:834-9.

7. Konkol RJ, Erickson BA, Doerr JK, et al. Seizures induced by the cocaine metabolite benzoylecgonine in rats. Epilepsia 1992;33:420-7.

8. Binelli A, Marisa I, Fedorova M, et al. First evidence of protein profile alteration due to the main cocaine metabolite (benzoylecgonine) in a freshwater biological model. Aquat Toxicol 2013;140-141:268-78.

9. Gonzalez-Marino I, Baz-Lomba JA, Alygizakis NA, et al. Spatio-temporal assessment of illicit drug use at large scale: evidence from 7 years of international wastewater monitoring. Addiction 2020;115:109-20.

10. Pal R, Megharaj M, Kirkbride KP, et al. Illicit drugs and the environment--a review. Sci Total Environ 2013;463464:1079-92.

11. Mendoza A, Lopez de Alda M, Gonzalez-Alonso S, et al. Occurrence of drugs of abuse and benzodiazepines in river waters from the Madrid Region (Central Spain). Chemosphere 2014;95:247-55.

12. Parolini M, Magni S, Castiglioni S, et al. Realistic mixture of illicit drugs impaired the oxidative status of the zebra mussel (Dreissena polymorpha). Chemosphere 2015;128:96-102.

13. Parolini M, Magni S, Castiglioni S, et al. Genotoxic effects induced by the exposure to an environmental mixture of illicit drugs to the zebra mussel. Ecotoxicol Environ Saf 2016;132:26-30.

14. De Felice B, Parolini M. Effects of single and combined exposure to cocaine and benzoylecgonine on the oxidative status of Mytilus galloprovincialis. Environ Toxicol Pharmacol 2020;80:103475.

15. Parolini M, De Felice B, Ferrario C, et al. Benzoylecgonine exposure induced oxidative stress and altered swimming behavior and reproduction in Daphnia magna. Environ Pollut 2018;232:236-44.

16. Parolini M, Bini L, Magni S, et al. Exposure to cocaine and its main metabolites altered the protein profile of zebrafish embryos. Environ Pollut 2018;232:603-14.

17. Parolini M, Pedriali A, Riva C, et al. Sub-lethal effects caused by the cocaine metabolite benzoylecgonine to the freshwater mussel Dreissena polymorpha. Sci Total Environ 2013;444:43-50.

18. Chen X, Zheng X, Zhan M, et al. Metabolic Enzymes of Cocaine Metabolite Benzoylecgonine. ACS Chem Biol 2016;11:2186-94.
19. Yadav MK, Short MD, Gerber C, et al. Removal of emerging drugs of addiction by wastewater treatment and water recycling processes and impacts on effluentassociated environmental risk. Sci Total Environ 2019;680:13-22.

20. Madden JA, Powers RH. Effect of cocaine and cocaine metabolites on cerebral arteries in vitro. Life Sci 1990;47:1109-14.

21. Madden JA, Konkol RJ, Keller PA, et al. Cocaine and benzoylecgonine constrict cerebral arteries by different mechanisms. Life Sci 1995;56:679-86.

22. Farooque U, Okorie N, Kataria S, et al. Cocaine-Induced Headache: A Review of Pathogenesis, Presentation, Diagnosis, and Management. Cureus 2020;12:e10128.

23. Jonsson S, O'Meara M, Young JB. Acute cocaine poisoning. Importance of treating seizures and acidosis. Am J Med 1983;75:1061-4.

24. Spivey WH, Euerle B. Neurologic complications of cocaine abuse. Ann Emerg Med 1990;19:1422-8.

25. Tseng CC, Derlet RW, Albertson TE. Cocaine-induced respiratory depression and seizures are synergistic mechanisms of cocaine-induced death in rats. Ann Emerg Med 1992;21:486-93.

26. Williams S. A FASEB sampler. American Societies for Experimental Biology. Science 1990;248:166.

27. Pascual-Leone A, Dhuna A, Altafullah I, et al. Cocaineinduced seizures. Neurology 1990;40:404-7.

28. Degenhardt L, Hall W. Extent of illicit drug use and dependence, and their contribution to the global burden of disease. Lancet 2012;379:55-70.

29. Cadet JL, Bisagno V, Milroy CM. Neuropathology of substance use disorders. Acta Neuropathol 2014;127:91-107.

30. Cunha-Oliveira T, Rego AC, Oliveira CR. Cellular and molecular mechanisms involved in the neurotoxicity of opioid and psychostimulant drugs. Brain Res Rev 2008;58:192-208.

31. Planeta CS, Lepsch LB, Alves R, et al. Influence of the dopaminergic system, CREB, and transcription factorkappaB on cocaine neurotoxicity. Braz J Med Biol Res 2013;46:909-15.

32. Lason W. Neurochemical and pharmacological aspects of cocaine-induced seizures. Pol J Pharmacol 2001;53:57-60.

33. Konkol RJ, Doerr JK, Madden JA. Effects of benzoylecgonine on the behavior of suckling rats: a preliminary report. J Child Neurol 1992;7:87-92.

34. Kaufmann RA, Armant DR. In vitro exposure of preimplantation mouse embryos to cocaine and benzoylecgonine inhibits subsequent development. 
Teratology 1992;46:85-9.

35. Covert RF, Schreiber MD, Tebbett IR, et al. Hemodynamic and cerebral blood flow effects of cocaine, cocaethylene and benzoylecgonine in conscious and anesthetized fetal lambs. J Pharmacol Exp Ther 1994;270:118-26.

36. Konkol RJ, Murphey LJ, Ferriero DM, et al. Cocaine metabolites in the neonate: potential for toxicity. J Child Neurol 1994;9:242-8.

37. Schuelke GS, Konkol RJ, Terry LC, et al. Effect of cocaine metabolites on behavior: possible neuroendocrine mechanisms. Brain Res Bull 1996;39:43-8.

38. Spear LP, Frambes NA, Kirstein CL. Fetal and maternal brain and plasma levels of cocaine and benzoylecgonine following chronic subcutaneous administration of cocaine during gestation in rats. Psychopharmacology (Berl) 1989;97:427-31.

39. Spear LP, Kirstein CL, Frambes NA. Cocaine effects on the developing central nervous system: behavioral, psychopharmacological, and neurochemical studies. Ann N Y Acad Sci 1989;562:290-307.

40. Collins LM, Pahl JA, Meyer JS. Distribution of cocaine and metabolites in the pregnant rat and fetus in a chronic subcutaneous injection model. Neurotoxicol Teratol 1999;21:639-46.

41. Chasnoff IJ, Lewis DE, Griffith DR, et al. Cocaine and pregnancy: clinical and toxicological implications for the neonate. Clin Chem 1989;35:1276-8.

42. Nassogne MC, Evrard P, Courtoy PJ. Selective direct toxicity of cocaine on fetal mouse neurons. Teratogenic implications of neurite and apoptotic neuronal loss. Ann N Y Acad Sci 1998;846:51-68.

43. Parolini M, Ghilardi A, Della Torre C, et al. Environmental concentrations of cocaine and its main metabolites modulated antioxidant response and caused cyto-genotoxic effects in zebrafish embryo cells. Environ Pollut 2017;226:504-14.

44. Spasiano D, Russo D, Vaccaro M, et al. Removal of benzoylecgonine from water matrices through UV254/ $\mathrm{H} 2 \mathrm{O} 2$ process: Reaction kinetic modeling, ecotoxicity and genotoxicity assessment. J Hazard Mater 2016;318:515-25.

45. Goodson HV, Hawse WF. Molecular evolution of the actin family. J Cell Sci 2002;115:2619-22.

46. Kalume DE, Okulate M, Zhong J, et al. A proteomic analysis of salivary glands of female Anopheles gambiae mosquito. Proteomics 2005;5:3765-77.

47. Yamaura K, Takahashi KG, Suzuki T. Identification and tissue expression analysis of C-type lectin and galectin in the Pacific oyster, Crassostrea gigas. Comp Biochem
Physiol B Biochem Mol Biol 2008;149:168-75.

48. Blank M, Mikkat S, Verleih M, et al. Proteomic comparison of two invasive polychaete species and their naturally occurring F1-hybrids. J Proteome Res 2012;11:897-905.

49. Pedriali A, Riva C, Parolini M, et al. A redox proteomic investigation of oxidative stress caused by benzoylecgonine in the freshwater bivalve Dreissena polymorpha. Drug Test Anal 2013;5:646-56.

50. Lowe DM, Fossato VU, Depledge MH. Contaminantinduced lysosomal membrane damage in blood cells of mussels Mytilus galloprovincialis from the Venice Lagoon: an in vitro study. Oceanographic Literature Review 1995;129:189-96.

51. Cheung CC, Zheng GJ, Lam PK, et al. Relationships between tissue concentrations of chlorinated hydrocarbons (polychlorinated biphenyls and chlorinated pesticides) and antioxidative responses of marine mussels, Perna viridis. Mar Pollut Bull 2002;45:181-91.

52. El-Shafey AF, Armstrong AE, Terrill JR, et al. Screening for increased protein thiol oxidation in oxidatively stressed muscle tissue. Free Radic Res 2011;45:991-9.

53. García-Cambero JP, García-Cortés H, Valcárcel Y, et al. Environmental concentrations of the cocaine metabolite benzoylecgonine induced sublethal toxicity in the development of plants but not in a zebrafish embryo-larval model. J Hazard Mater 2015;300:866-72.

54. Macht DI, Livingston MB. Effect of Cocaine on the Growth of Lupinus Albus. A Contribution To the Comparative Pharmacology of Animal and Plant Protoplasm. J Gen Physiol 1922;4:573-84.

55. Chiavola A, Boni MR, Di Marcantonio C, et al. A laboratory-study on the analytical determination and removal processes of THC-COOH and bezoylecgonine in the activated sludge reactor. Chemosphere 2019;222:83-90.

56. Valhondo C, Carrera J, Ayora C, et al. Behavior of nine selected emerging trace organic contaminants in an artificial recharge system supplemented with a reactive barrier. Environ Sci Pollut Res Int 2014;21:11832-43.

57. Andreozzi R. Advanced oxidation processes (AOPs) for water purification and recovery. Catalysis Today 1999;53:51-9.

58. Catala M, Dominguez-Morueco N, Migens A, et al. Elimination of drugs of abuse and their toxicity from natural waters by photo-Fenton treatment. Sci Total Environ 2015;520:198-205.

59. Mackulak T, Birosova L, Bodik I, et al. Zerovalent iron and 
iron(VI): Effective means for the removal of psychoactive pharmaceuticals and illicit drugs from wastewaters. Sci Total Environ 2016;539:420-6.

60. Russo D, Spasiano D, Vaccaro M, et al. Investigation on the removal of the major cocaine metabolite (benzoylecgonine) in water matrices by UV254/ $\mathrm{H} 2 \mathrm{O} 2$ process by using a flow microcapillary film array photoreactor as an efficient experimental tool. Water Res 2016;89:375-83.

61. Huerta-Fontela M, Galceran MT, Ventura F. Stimulatory drugs of abuse in surface waters and their removal in a conventional drinking water treatment plant. Environ Sci Technol 2008;42:6809-16.

62. Rodayan A, Segura PA, Yargeau V. Ozonation of wastewater: removal and transformation products of drugs of abuse. Sci Total Environ 2014;487:763-70.

63. Rodayan A, Afana S, Segura PA, et al. Linking drugs of abuse in wastewater to contamination of surface and drinking water. Environ Toxicol Chem 2016;35:843-9.

64. Zheng F, Yang W, Ko MC, et al. Most efficient cocaine hydrolase designed by virtual screening of transition states. J Am Chem Soc 2008;130:12148-55.

65. Pan Y, Gao D, Yang W, et al. Computational redesign of human butyrylcholinesterase for anticocaine medication. Proc Natl Acad Sci U S A 2005;102:16656-61.

66. Xue L, Ko MC, Tong M, et al. Design, preparation, and characterization of high-activity mutants of human butyrylcholinesterase specific for detoxification of cocaine. Mol Pharmacol 2011;79:290-7.

67. Zheng F, Xue L, Hou S, et al. A highly efficient cocainedetoxifying enzyme obtained by computational design. Nat Commun 2014;5:3457.

Cite this article as: Wang J, Deng X, Wu Y, Huang Y, Hou S, Zhang Y, Qiu T, Tong J, Chen X. Sub-lethal toxicity and elimination of the cocaine metabolite, benzoylecgonine: a narrative review. Ann Palliat Med 2021;10(6):6936-6947. doi: 10.21037/apm-21-243
68. Gao D, Narasimhan DL, Macdonald J, et al. Thermostable variants of cocaine esterase for long-time protection against cocaine toxicity. Mol Pharmacol 2009;75:318-23.

69. Fang L, Hou S, Xue L, et al. Amino-acid mutations to extend the biological half-life of a therapeutically valuable mutant of human butyrylcholinesterase. Chem Biol Interact 2014;214:18-25.

70. Nasser AF, Fudala PJ, Zheng B, et al. A randomized, double-blind, placebo-controlled trial of RBP-8000 in cocaine abusers: pharmacokinetic profile of rbp- 8000 and cocaine and effects of RBP-8000 on cocaine-induced physiological effects. J Addict Dis 2014;33:289-302.

71. Zheng F, Zhan CG. Are pharmacokinetic approaches feasible for treatment of cocaine addiction and overdose? Future Med Chem 2012;4:125-8.

72. Cohen-Barak O, Wildeman J, van de Wetering J, et al. Safety, pharmacokinetics, and pharmacodynamics of TV1380, a novel mutated butyrylcholinesterase treatment for cocaine addiction, after single and multiple intramuscular injections in healthy subjects. J Clin Pharmacol 2015;55:573-83.

73. Shram MJ, Cohen-Barak O, Chakraborty B, et al. Assessment of Pharmacokinetic and Pharmacodynamic Interactions Between Albumin-Fused Mutated Butyrylcholinesterase and Intravenously Administered Cocaine in Recreational Cocaine Users. J Clin Psychopharmacol 2015;35:396-405.

74. Brimijoin S, Gao Y, Anker JJ, et al. A cocaine hydrolase engineered from human butyrylcholinesterase selectively blocks cocaine toxicity and reinstatement of drug seeking in rats. Neuropsychopharmacology 2008;33:2715-25. 